Marquette University

e-Publications@Marquette

9-1-2016

Development of a Barriers Scale to Predict Early Treatment Success for Young Children in Poverty with Behavior Problems

\author{
Brittany Lynn Gresl \\ Marquette University \\ Robert A. Fox \\ Marquette University, robert.fox@marquette.edu \\ Lauryn A. Besasie \\ Marquette University
}

Accepted version. Clinical Practice in Pediatric Psychology, Vol. 4, No. 3 (September 2016): 249-262.

DOI. (C) 2016 American Psychological Association. Used with permission. 


\title{
Development of a Barriers Scale to Predict Early Treatment Success for Young Children in Poverty with Behavior Problems
}

\author{
Brittany L. Gresl \\ Department of Counselor Education and Counseling Psychology, \\ Marquette University, \\ Milwaukee, WI \\ Robert A. Fox \\ Department of Counselor Education and Counseling Psychology, \\ Marquette University, \\ Milwaukee, WI \\ Lauryn A. Besasie \\ Department of Counselor Education and Counseling Psychology, \\ Marquette University, \\ Milwaukee, WI
}

This research was supported in part by grants from the Aurora Health Care Better Together Fund, the Charles D. Jacobus Family

Clinical Practice in Pediatric Psychology, Vol 4, No. 3 (September 2016): pg. 249-262. DOI. This article is (C American Psychological Association and permission has been granted for this version to appear in e-Publications@Marquette. American Psychological Association does not grant permission for this article to be further copied/distributed or hosted elsewhere without the express permission from American Psychological Association. 
Foundation, the Exchange Clubs of Greater Milwaukee Charitable Foundation, the Greater Milwaukee Foundation, the Helen Bader Foundation, the Hearst Foundation, the Roger and Cindy Schaus Family, the United Way, and the Zilber Family Foundation. We'd like to acknowledge the support of the professional staff and graduate students who implemented this project and the families with young children that agreed to participate in it.

Parent and child therapy (PCT) programs that teach parents child development and behavior management knowledge and skills have emerged over the past several years as a successful approach for addressing conduct problems in preschool children (Poulou, 2015). An ongoing challenge has been to first engage (Harrison, McKay, \& Bannon, 2004) and then maintain (McCabe, 2002) families in treatment for a sufficient length of time to achieve positive outcomes. Only approximately half of families who receive mental health services for their children meet the parents' and therapists' goals for treatment (Nock \& Ferriter, 2005), with lower success rates for low-income families (43\%; Fox \& Holtz, 2009). Efforts to understand why some families are successful and others are not have focused on parent, child, and family demographic characteristics and pretreatment variables such as socioeconomic status (SES), maternal mental health, and child symptom severity (Reyno \& McGrath, 2006). Other barriers to treatment (e.g., lack of transportation, child care, history of missed appointments) also have been identified as potential predictors of treatment success (McCabe, 2002).

More recently, the treatment setting (e.g., home vs. office setting) has come under scrutiny (Thomas \& Zimmer-Gembeck, 2007) as a possible contributing factor in the success of parent-child therapy programs. In one study comparing a parent-child therapy program in a home versus a clinic setting, only $31 \%$ of families from a wide range of socioeconomic levels completed the treatment program (Lanier et al., 2011). This study concluded that both settings achieved positive results, with the office setting producing more-rapid changes in the child and parent outcomes. In a meta-analysis of 24 parent-child therapy studies (Thomas \& Zimmer-Gembeck, 2007), 42\% did not report success rates (success rate $=100 \%-$ attrition $\%$ ). Of those that did, the range of success rates ranged from $58 \%$ to $82 \%$. Of these studies, the treatment setting was not reported but appeared to

Clinical Practice in Pediatric Psychology, Vol 4, No. 3 (September 2016): pg. 249-262. DOI. This article is (C) American Psychological Association and permission has been granted for this version to appear in e-Publications@Marquette. American Psychological Association does not grant permission for this article to be further copied/distributed or hosted elsewhere without the express permission from American Psychological Association. 
be clinic-based. Also, most parent-child therapy studies addressed families who came largely from middle SES levels. For families who live below the federal poverty level and receive parent-child therapy in their homes, the story of success changes. Success rates for these families have been reported to range between $40 \%$ and $68 \%$ (Carrasco \& Fox, 2012; Gresl, Fox, \& Fleischmann, 2014). With homebased parent-child therapy requiring more resources to provide than does office-based therapy (e.g., therapists' traveling to and from homes is time consuming and not reimbursable as an outpatient service; homes in unsafe neighborhoods require special therapist safety training and backup support systems), it is important to identify those families who are ready and motivated to benefit from treatment and those who are not.

In an effort to identify families who may struggle to be successful in parent-child therapy, Kazdin, Holland, Crowley, and Breton (1997) developed a model to conceptualize barriers to treatment that divided barriers into four thematic areas: stressors and obstacles that compete with treatment, treatment demands and issues, perceived relevance of treatment, and relationship with the therapist. A scale that formally assesses these areas was developed for both parents and therapists, the Barriers to Treatment Participation Scale (BTPS; Kazdin et al., 1997). The BTPS includes 44 items that address these four themes as well as a separate Critical Events Scale (14 items) to distinguish perceived barriers associated with treatment participation from specific life-changing events (e.g., moving, change of job). Families scoring high on perceived barriers are less likely to experience treatment success, spend fewer weeks in treatment, and have higher rates of cancellation prior to dropping out. Although the BTPS provides useful information regarding prediction of treatment outcomes, an analysis of Kazdin et al.'s (1997) study revealed a number of limitations: (a) It was completed by parents and therapists at the end of treatment and therefore may have been influenced by recall bias and did not afford clinicians the opportunity to address barriers before they interfered with treatment; (b) the length and format for administration were time consuming, thus limiting its application in busy health care and other community-based settings; and (c) the majority of the test sample was Caucasian (63.6\%) with reported incomes above the federal poverty level, thus limiting its 
generalization to a diverse, low-income, urban population of children and families (Colonna-Pydyn, Gjesfjeld, \& Greeno, 2007).

The purpose of the present study was to develop and pilot a new measure to assess barriers to treatment participation in primarily low-income, urban minority parents receiving home-based therapy for their very young child's behavior problems. This scale, the Treatment Barriers Scale (TBS), guided by theory and research on barriers to treatment (Nock \& Ferriter, 2005; Snell-Johns, Mendez, \& Smith, 2004), was designed to provide a brief assessment of barriers to treatment from the clinician's perspective early in the treatment process. This study determined the preliminary psychometrics of the TBS and its use with low-income families with very young children. The final goal of this study was to determine whether the TBS could predict early success in treatment. Accurate identification of barriers experienced by families early in treatment may advance the understanding of treatment success and subsequently serve as the basis for providing more-effective interventions to retain families until treatment goals are achieved.

\section{Method}

\section{Participants}

The participants in this study were 330 children from the Midwest who were consecutively referred to a clinic that was specifically developed to address mental health problems in very young children (Fox, Keller, Grede, \& Bartosz, 2007) and who met the study's eligibility criteria. Children were referred to the clinic by over 50 community-based sources, including medical providers (e.g., pediatric psychologists, nurses, physicians, and social workers), community-based health and social service agencies (e.g., child protective services, children's hospitals, and preschools), and parents themselves. Eligibility criteria for this study included the following: (a) the child was under 6 years of age; (b) the child did not have significant physical disabilities, serious medical conditions, or symptoms indicative of a pervasive developmental disorder or significant intellectual disability; (c) the child was referred for significant behavior or emotional concerns (e.g., aggression, 
oppositional defiance, tantrums, hyperactivity, destructiveness, selfinjury, separation anxiety); (d) the family completed an intake evaluation and three treatment sessions; and (e) the child's parent or guardian signed a consent form. If the parent or guardian declined to participate in this research project (this was the case concerning approximately $3 \%$ of eligible children), the same treatment program was offered to the family, but their data were not included or analyzed in this study, due to the provisions of the consent form. The average age of the participating children was 3.17 years $(S D=1.07) ; 67 \%$ were male. The children's race included 49.4\% African American, $21.2 \%$ Latino, $17.3 \%$ multiracial, and $12.1 \%$ Caucasian. Of the sample, $48 \%$ had a mild developmental delay and nearly all children met the criteria for a psychiatric disorder, with oppositional defiant disorder being the most common (44.5\%). The average age of the primary caretaker was 30.04 years $(S D=8.51)$, and the majority of families were receiving public assistance $(87.9 \%)$, which required that they meet the federal definition of poverty.

\section{Intervention}

\section{Treatment program}

The Early Pathways Program (EPP) for young children, a homebased PCT program designed for families in poverty, was used (Fung \& Fox, 2014; Harris, Fox, \& Love, 2015). EPP includes four main treatment elements: (a) strengthening the parent/child relationship through child-led play; (b) teaching parents to maintain appropriate developmental expectations for their child and to learn cognitive strategies to avoid emotionally and behaviorally overreacting to their child's challenging behaviors in a negative manner; (c) using techniques to strengthen the child's prosocial behaviors such as positive reinforcement, establishing home routines, and giving good instructions; and (d) employing limit-setting strategies to reduce the child's challenging behaviors such as redirection, ignoring, response cost, and time-out. Treatment strategies and their rationale were explained to the parent and directly modeled by the clinician. Parents also practiced each strategy with their child during the treatment sessions and received immediate feedback from the clinician. The treatment program was designed to be completed in eight once-

Clinical Practice in Pediatric Psychology, Vol 4, No. 3 (September 2016): pg. 249-262. DOI. This article is (C) American Psychological Association and permission has been granted for this version to appear in e-Publications@Marquette. American Psychological Association does not grant permission for this article to be further copied/distributed or hosted elsewhere without the express permission from American Psychological Association. 
weekly treatment sessions; however, often more sessions were needed to meet the treatment goals. Treatment sessions were approximately $90 \mathrm{~min}$ in length. Past treatment outcomes for EPP have demonstrated decreased frequency of the child's challenging behaviors, increased positive parent-child interactions during play, decreased parental reliance on verbal and corporal punishment for discipline, improved parental expectations, and higher levels of nurturing at posttreatment (Fox \& Holtz, 2009; Harris, Fox, \& Love, 2015). These results have been shown to be effective across ethnicity, with low-income African American, Caucasian, and Latino families showing similar levels of improvement with treatment (Gresl et al., 2014); with children both with and without mild developmental delays (Holtz, Carrasco, Mattek, \& Fox, 2009); and for achieving long-term maintenance of treatment gains at 1-year follow-up (Fung, Fox, \& Harris, 2014).

\section{Clinician training}

Clinicians were licensed therapists and graduate students in psychology and community counseling programs who received practicum and internship course credit for their participation in this study. All clinicians received extensive training and supervision in four modules: (a) working with diverse families of young children with and without developmental delays who live in poverty and maintaining personal safety in the home setting in often unsafe, urban neighborhoods; (b) clinical skills needed for interacting with children less than 6 years of age and their caregivers; (c) treatment theory, program content, and procedures; and (d) assessment administration and data collection. Clinicians initially shadowed veteran clinicians on home visits and gradually assumed responsibility for more of the sessions until they were competent on the basis of a supervisorcompleted fidelity checklist to lead sessions on their own. Each clinician participated in ongoing weekly supervision (group and individual) for assistance on specific issues that arose with families and for feedback on their performance while implementing the treatment program.

Clinical Practice in Pediatric Psychology, Vol 4, No. 3 (September 2016): pg. 249-262. DOI. This article is (C) American Psychological Association and permission has been granted for this version to appear in e-Publications@Marquette. American Psychological Association does not grant permission for this article to be further copied/distributed or hosted elsewhere without the express permission from American Psychological Association. 
NOT THE PUBLISHED VERSION; this is the author's final, peer-reviewed manuscript. The published version may be accessed by following the link in the citation at the bottom of the page.

\section{Instruments}

Intake form

An intake form completed by the intake clinician during the first session included basic demographic data on the caregiver and child, confirmation of family receipt of public assistance and annual household income to establish poverty status, and background information on the referral concern.

\section{Early Childhood Behavior Screen (ECBS)}

The ECBS (Holtz \& Fox, 2012) is a 20-item self-report instrument developed specifically for very young children ( 0 to 5 years old) from low-income backgrounds. The ECBS includes 10 positive behavior items (e.g., listens to you, shares toys) and 10 challenging behavior items (e.g., hits others, has temper tantrums) and is written at a 3.9 grade level. The scale instructions asked caregivers to rate each item on the basis of the frequency of their child's behavior over the past week using a 3-point scale ( $1=$ rarely/never, $2=$ sometimes, $3=$ almost always/always). Total scores on the ECBS's Challenging Behavior Scale (CBS) ranged from 10 to 30, with higher scores indicating a higher frequency of challenging behaviors. Total scores on the ECBS's Positive Behavior Scale (PBS) ranged from 10 to 30, with higher scores indicating a higher frequency of positive behaviors. Field-testing of the ECBS was conducted with a representative, diverse sample of 439 parents from a low-income urban community. Examination of reliability of the ECBS found the CBS (.87) and PBS (.92) obtained good levels of internal consistency. A recent study (Harris, Fox, \& Holtz, 2015) with a diverse sample of 428 clinicreferred children and 245 non-clinic-referred children from families in poverty demonstrated a good fit for the original factor structure using confirmatory factor analyses. Sensitivity rates for the cutoff scores ranged from 0.76 to 0.83 , and specificity rates ranged from 0.88 to 0.95 , meeting Glascoe's (2005) recommendation for screening instruments. Adequate test-retest reliability (0.76) and internal consistency (0.91) for the CBS were reported. 
NOT THE PUBLISHED VERSION; this is the author's final, peer-reviewed manuscript. The published version may be accessed by following the link in the citation at the bottom of the page.

\section{Procedure}

Approval for the study was obtained from the authors' Institutional Review Board. Items for the scale were initially developed on the basis of a review of current measures, such as the BTPS (Kazdin et al., 1997), and a review of the theoretical and empirical literature on barriers to treatment (Nock \& Ferriter, 2005; Snell-Johns et al., 2004). The language used in the development of the items was written in concise and concrete language so clinicians could complete it quickly and accurately with parents from all educational levels. An effort was also made to include items that would capture the unique barriers experienced by low-income families. After an initial item list was generated, a sample of professionals ranging in age from 22 to 58 ( $n=12 ; 2$ male) with a wide range of experience ( $1-35$ years) in working with young urban children and their families (e.g., psychologist, counselors, doctoral students) were recruited to rate each item on clarity (e.g., clear, somewhat clear, unclear) and relevance (e.g., relevant, somewhat relevant, not relevant). Adjustments to the original items were made according to the following criteria: (a) If $80 \%$ of the raters considered any item not relevant, it was removed from the measure, and (b) if $80 \%$ of the professional raters considered any item unclear, the wording of the item was revised. Of the 23 original items, 17 items were retained for the final scale. During implementation of EPP, clinicians rated each item following the third treatment session on the basis of a 3-point Likert scale $(1=$ good, 2 =fair, $3=$ poor $)$; each of these ratings were provided descriptive statements to ensure clinicians understood the intent of each item (see Figure 1 for the TBS items and rating scale) and thus improve its reliability. The third session of treatment was selected to administer the TBS so that clinicians had the opportunity to become more familiar with the family and observe characteristics that could be potential barriers to treatment (e.g., chaotic home environment, excessive number of people in a small apartment, lack of availability of toys for the child, unmet child health needs). It also allowed the clinician to cover a significant amount of the treatment protocol across the first three sessions to gauge parent motivation, engagement in the sessions, and cooperation with carrying out the treatment procedures. 
NOT THE PUBLISHED VERSION; this is the author's final, peer-reviewed manuscript. The published version may be accessed by following the link in the citation at the bottom of the page.

Child Name: Clinician: Date:

\section{Treatment Process Barriers Subscale}

1. Caregiver participation in session Good Fair Poor

Good= listens, learns, does homework; treatment plan filled out $75-100 \%$ of the time; engages in conversation about treatment; asks questions; responsive to feedback

Fair = treatment plan filled out $50-75 \%$ of time; parent doesn't ask many questions or readily integrate feedback; reports doing homework but does not track it

Poor $=$ appears disinterested in treatment; treatment Plan regularly lost or left blank; appears that parent fills-out treatment plan in other room before giving to clinician; sessions feel like "pulling teeth," parent communicates not wanting to be at session

\section{Caregiver implementation of treatment}

Good

Fair Poor

Good = use treatment strategies correctly and consistently

Fair = problems with consistency; has difficulty implementing techniques correctly (e.g., does not do time-out properly); struggles with remembering to stop and think

Poor = doesn't understand techniques; can't implement techniques despite ongoing clinician support

\section{Caregiver perception of change}

Good

Fair

Poor

Good = accurate as compared to clinician perception; when change occurs, caregiver recognizes it appropriately

Fair = somewhat accurate as compared to clinician perception; caregiver perceives change but not as much/little as clinician; needs clinician guidance to recognize change

Poor $=$ inaccurate as compared to clinician perception; caregiver does not recognize change despite clinician guidance, argues against evidence of change

\section{Treatment attendance}

Good

Fair

Poor

Good $=100 \%$; caregiver has attended all three sessions without cancellation

Fair $=66 \%$; one cancelled session due to reasonable excuse (e.g. child sick, family emergency)

Poor $=0-33 \%$; multiple cancellations; one or more no-shows

Figure 1. The Treatment Barrier Scale (TBS), including subscales, items, and rating definitions. Good $=1$; Fair $=2$; Poor $=3$. TBS total score range: $17-$

Clinical Practice in Pediatric Psychology, Vol 4, No. 3 (September 2016): pg. 249-262. DOI. This article is (C) American Psychological Association and permission has been granted for this version to appear in e-Publications@Marquette. American Psychological Association does not grant permission for this article to be further copied/distributed or hosted elsewhere without the express permission from American Psychological Association. 
NOT THE PUBLISHED VERSION; this is the author's final, peer-reviewed manuscript. The published version may be accessed by following the link in the citation at the bottom of the page.

51. Higher TBS total scores indicate the presence of more barriers. 5. Clinician observation of change

Good

Fair

Poor

Good = evidence of positive change in child's behavior

Fair = little or no evidence of positive change in child's behavior

Poor $=$ child's behaviors get worse

6. Clinician sense of parent motivation $\quad$ Good $\quad$ Fair $\quad$ Poor

Good = caregiver is working to improve environment for child/family/self, other commitments are scheduled around treatment; caregiver may be making some sacrifices to attend treatment (e.g., adjusting work schedule, keeping child home from daycare/school)

Fair = caregiver appears unsure if therapy is helpful; other commitments sometimes take priority over treatment; caregiver pressured into therapy by another individual but is trying to engage

Poor = other commitments consistently take priority over treatment; caregiver communicating that treatment is not helpful; caregiver in treatment to meet demands of other service providers

\section{Quality of caregiver/clinician rapport}

Good

Fair

Poor

Good = caregiver appears comfortable talking about child's problem behaviors with clinician; caregiver open to feedback; caregiver appears to trust clinician judgment and knowledge

Fair = caregiver appears uncomfortable talking about child's problem behaviors; caregiver appears defensive when given feedback; caregiver may question clinician judgment and/or knowledge

Poor = caregiver presents as closed-off when talking with clinician; caregiver resistant to feedback; caregiver does not trust clinician's judgment/knowledge; overt breach of trust by caregiver has occurred (e.g., lying, manipulating)

Operational Barriers Subscale

8. Home routines

Good

Fair

Poor

Good = regular home routines apparent; consistent bedtime routine; structured daily activities; predictable daily schedule; regular mealtimes

Fair = some home routines; bedtime and mealtimes are inconsistent; child sometimes left to fend for self; child is often given snacks in lieu of meals

Poor= minimal or no routines; chaotic home; child goes to bed when tired; no formal mealtimes

Figure 1. The Treatment Barrier Scale (TBS), including subscales, items, and rating definitions. Good $=1$; Fair $=2$; Poor $=3$. TBS total score range: $17-$

Clinical Practice in Pediatric Psychology, Vol 4, No. 3 (September 2016): pg. 249-262. DOI. This article is (C) American Psychological Association and permission has been granted for this version to appear in e-Publications@Marquette. American Psychological Association does not grant permission for this article to be further copied/distributed or hosted elsewhere without the express permission from American Psychological Association. 
NOT THE PUBLISHED VERSION; this is the author's final, peer-reviewed manuscript. The published version may be accessed by following the link in the citation at the bottom of the page.

51. Higher TBS total scores indicate the presence of more barriers.

9. Basic needs Good $\quad$ Fair

Good = minimal or no concerns; basic needs (shelter, food, clothing, safety) met

Fair = moderate concerns; basic needs stressed; caregiver working multiple jobs; adequate food/diapers/clothing/toys a concern

Poor= serious concerns; caregiver struggling to meet basic needs of family; threat of eviction; lack of clothes; utilities turned off; significant sanitation concerns

10. Quality of parental supervision $\quad$ Good $\quad$ Fair $\quad$ Poor

Good = parent keeps child within sight; aware of what child is doing; child safety not at risk

Fair = parent sometimes becomes distracted and loses track of child; parent thinks child can take care of self despite getting into trouble at times

Poor= child is regularly unsupervised; child safety is at-risk; child may injure others at these times

11. Multiple caregiver cooperation

Good

Fair

Poor

Good = caregivers mostly agree; disagreements about child rearing are infrequent

Fair = occasional disagreements; caregivers sometimes undermine each other in front of the child

Poor $=$ overt differences of opinions that are a barrier to treatment progression; clinician spends significant amount of time trying to address impact of disagreements

\begin{tabular}{llll}
\hline 12. Support for primary caregiver & Good & Fair & Poor
\end{tabular}

Good = supportive secondary caregiver; at least one other supportive adult or older child who helps and is engaged in treatment

Fair = occasional help; secondary caregiver or other adults somewhat interested in treatment

Poor= little to no help; secondary caregiver or other adults uninterested in treatment

13. Caregiver mental health $\quad$ Good $\quad$ Fair $\quad$ Poor

Good = no concerns; existing mental health problems are stable and do not impact treatment

Fair = mental health problems sometimes impact treatment (e.g., mom has difficulty responding accurately or immediately because of mood disorder)

Poor= caregiver's mental health is a significant barrier to treatment progression

Figure 1. The Treatment Barrier Scale (TBS), including subscales, items, and rating definitions. Good $=1$; Fair $=2$; Poor $=3$. TBS total score range: $17-$

Clinical Practice in Pediatric Psychology, Vol 4, No. 3 (September 2016): pg. 249-262. DOI. This article is (C) American Psychological Association and permission has been granted for this version to appear in e-Publications@Marquette. American Psychological Association does not grant permission for this article to be further copied/distributed or hosted elsewhere without the express permission from American Psychological Association. 
NOT THE PUBLISHED VERSION; this is the author's final, peer-reviewed manuscript. The published version may be accessed by following the link in the citation at the bottom of the page.

51. Higher TBS total scores indicate the presence of more barriers.

14. Caregiver physical health $\quad$ Good $\quad$ Fair $\quad$ Poor

Good = no concerns; existing physical health problems are stable and do not impact treatment

Fair = physical health problems sometimes impact treatment (e.g. mom has difficulty playing with child due to obesity or pregnancy)

Poor $=$ caregiver's physical health is a significant barrier to treatment progression

15. Caregiver learning ability $\quad$ Good $\quad$ Fair $\quad$ Poor

Good = understands reason behind techniques; readily picks-up techniques; comes up with solutions to new situations independently

Fair = understands techniques only at face value; struggles to implement techniques; needs lots of repetition under clinician guidance; cannot adapt techniques to new situations

Poor = doesn't understand techniques; can't implement techniques despite ongoing clinician support

16. Caregiver ability to manage stress Good Fair Poor

Good = life-stress experienced by caregiver does not impact treatment; may have multiple life-stressors but copes well and is able to function

Fair = struggling to manage life stress or is over-stressed; life-stress slightly impacts treatment

Poor= poor life-stress management or is severely over-stressed; life-stress significantly effects caregiver's ability to function; life-stress significantly impacts treatment

\begin{tabular}{|c|c|c|}
\hline 17. Caregiver & treatment focus on child & Fair \\
\hline \multicolumn{3}{|c|}{$\begin{aligned} \text { Good }= & \text { discussion during session is consistently focused on treatment or child's } \\
& \text { behavior, little discussion of caregiver's personal problems; caregiver concerns } \\
& \text { surround how to correctly implement treatment strategies }\end{aligned}$} \\
\hline Fair $=$ & $\begin{array}{l}\text { discussion is mostly focused on treatment or child' } \\
\text { sometimes is focused on caregiver's personal prob } \\
\text { goes off on tangents }\end{array}$ & $\begin{array}{l}\text { ior; discussion } \\
\text { aregiver occasionally }\end{array}$ \\
\hline Poor $=$ & $\begin{array}{l}\text { discussion during session is dominated by caregiv } \\
\text { tangential; difficult to keep treatment on track; fe } \\
\text { more than for child }\end{array}$ & $\begin{array}{l}\text { caregiver is very } \\
\text { erapy for caregiver }\end{array}$ \\
\hline
\end{tabular}

Figure 1. The Treatment Barrier Scale (TBS), including subscales, items, and rating definitions. Good $=1$; Fair $=2$; Poor $=3$. TBS total score range: $17-$ 51 . Higher TBS total scores indicate the presence of more barriers.

\section{Results}

A principal components factor analysis was used to determine the initial overall factor structure of the items on the Treatment Barrier Scale (TBS). Factors were extracted with eigenvalues greater than 1.0, and a parallel analysis with the Monte Carlo principal components analysis (PCA) program confirmed the overall factor structure for the scale. A scree plot was examined to further confirm the factor structure. Items that obtained factor loadings greater than .40 were

Clinical Practice in Pediatric Psychology, Vol 4, No. 3 (September 2016): pg. 249-262. DOI. This article is (C) American Psychological Association and permission has been granted for this version to appear in e-Publications@Marquette. American Psychological Association does not grant permission for this article to be further copied/distributed or hosted elsewhere without the express permission from American Psychological Association. 
identified for further analyses. Items that "cross-loaded" at .40 or higher on two or more factors were either discarded or assigned to the factor that had the highest loading on the basis of the clinical importance of the item (Tabachnick \& Fidell, 2007). A varimax rotation was utilized to determine the most meaningful factor structure. Means, standard deviations, skewness, and kurtosis for the 17 TBS items were computed. The Kaiser-Meyer-Olkin measure of sampling adequacy $(\mathrm{KMO}=.89)$ indicated a high degree of common variance among the items, suggesting that the factors resulting from the analysis accounted for a substantial amount of the variance. Bartlett's test of sphericity was significant, $\mathrm{X}^{2}(136)=2,031.160, p<.001$, indicating that no assumptions were violated. Four factors with eigenvalues greater than 1 were initially extracted. The parallel analysis with the Monte Carlo PCA program resulted in retaining two of the four original factors. A scree plot supported this two-factor structure. The factor analysis was rerun on all of the items extracting only two factors because the remaining two-factor structure provided the best representation of the scale. The two factors demonstrated a moderate correlation with one another $(r=.68)$, but given the two-factor structure proposed by the PCA, the parallel analysis, and the scree plot, both factors were retained for further analysis. The 17 items together explained $44.65 \%$ of the total variance.

Of the 17 items, seven items loaded on the first factor. This factor had an eigenvalue of 6.25 and explained $37 \%$ of the variance. Items included caregiver participation, caregiver implementation of treatment, caregiver perception of change, treatment attendance, clinician observation of change, clinician sense of parent motivation, and the quality of the caregiver and clinician relationship. Given the emphasis on barriers related to the process of treatment, Factor 1 was entitled Treatment Process Barriers. A reliability analysis revealed the internal consistency for this factor was .82 . The 10 remaining items loaded on Factor 2, Operational Barriers, which had an eigenvalue of 1.34 and explained $8 \%$ of the variance. It comprised items related to caregiver ability to meet child needs in the home environment-items regarding established home routines, basic needs met, quality of caregiver supervision, caregiver cooperation, caregiver support, caregiver mental health, caregiver physical health, caregiver learning ability, caregiver ability to manage stress, and caregiver treatment focus on child. A reliability analysis revealed the internal consistency

Clinical Practice in Pediatric Psychology, Vol 4, No. 3 (September 2016): pg. 249-262. DOI. This article is (C) American Psychological Association and permission has been granted for this version to appear in e-Publications@Marquette. American Psychological Association does not grant permission for this article to be further copied/distributed or hosted elsewhere without the express permission from American Psychological Association. 
NOT THE PUBLISHED VERSION; this is the author's final, peer-reviewed manuscript. The published version may be accessed by following the link in the citation at the bottom of the page.

for this factor was .80 . The factor loadings for each item by subscale are shown in Table 1.

Table 1

Treatment Barriers Scale Items by Factor and Factor Loadings for Each Item

\begin{tabular}{lc}
\hline \multicolumn{1}{c}{ Factor and item } & Factor loading \\
\hline Treatment Process Barriers & \\
Caregiver participation in session & .814 \\
Caregiver implementation of treatment & .657 \\
Caregiver perception of change & .598 \\
Treatment attendance & .462 \\
Clinician observation of change & .452 \\
Clinician sense of caregiver & .840 \\
motivation & \\
Quality of caregiver/clinician rapport & .782 \\
Operational Barriers & .539 \\
Home routines & .659 \\
Basic needs & .573 \\
Quality of parental supervision & .509 \\
Multiple caregiver cooperation & .462 \\
Support for primary caregiver & .727 \\
Caregiver mental health & .346 \\
Caregiver physical health & .504 \\
Caregiver learning ability & .683 \\
Caregiver ability to manage stress & .383 \\
Caregiver treatment focus on child & \\
\hline
\end{tabular}

A hierarchical logistic regression was performed to assess the extent to which scores on the TBS predicted early treatment success. A reliable change index (Jacobson \& Truax, 1991) on the ECBS's Challenging Behavior Scale (CBS) was utilized to operationalize early treatment success such that children who demonstrated reliable change on the ECBS by the third treatment session in comparison to their intake scores were assigned to the successful early treatment group, and children who did not demonstrate reliable change constituted the unsuccessful early treatment group. A change of 5 points was established to meet the reliable change criterion on the basis of a standard deviation of 4.23 and a coefficient alpha of .87 for the CBS (Fung et al., 2014). Of the 330 participants, 207 (62.7\%) met the 5-point change by the third session, showing how relatively quickly young children's behaviors can improve when parents follow the treatment program. We used $t$ tests to compare continuous variables and chi-square tests to compare categorical variables between groups that experienced early success in treatment and those that did not. The two groups did not differ significantly on children's ages, primary

Clinical Practice in Pediatric Psychology, Vol 4, No. 3 (September 2016): pg. 249-262. DOI. This article is (C) American Psychological Association and permission has been granted for this version to appear in e-Publications@Marquette. American Psychological Association does not grant permission for this article to be further copied/distributed or hosted elsewhere without the express permission from American Psychological Association. 
caretakers' ages, children's gender or race, or the presence of a developmental delay or a psychiatric diagnosis in the children. There was a trend ( $p=.055)$ for more early successful participants to come from families in poverty $(90.3 \%)$ than early unsuccessful families $(83.6 \%)$. There was a significant difference, $t(325)=7.99, p<.001$, between the two groups on the CBS, with the early successful group scoring higher $(M=23.98, S D=3.38)$ than did the early unsuccessful group $(M=20.51, S D=4.39)$. A significant difference, $t(325)=1.97$, $p=.05$, was also found on the ECBS's Positive Behavior Scale (PBS), with the early successful group scoring lower $(M=21.81, S D=3.16)$ than did the early unsuccessful group $(M=22.50, S D=3.02)$. Finally, the early successful group $(M=23.61, S D=5.66)$ scored significantly lower on the TBS than did the early unsuccessful group $(M=25.76$, $S D=6.19), t(325)=3.21, p<.001$.

The regression model contained eight independent variables, which were entered into the regression in three blocks. Six variables (child's age, child's race, child's gender, public assistance, presence of a developmental delay, and primary caretaker age) were entered into Block 1 of the regression. Block 2 included the same six variables plus a measure of symptom severity (e.g., CBS score), and Block 3 included the seven variables in Block 2 plus aggregate scores from the TBS. Although the two TBS factors yielded important information to help clinicians identify specifically which facet of treatment barriers may be impacting their case, the scores were theoretically and statistically similar enough (moderately correlated) and internally consistent ( .88$)$ to justify being combined into one overall composite score to create a more parsimonious model for analyses. The results of the regression are shown in Table 2 . Block 1 was not significant, $x^{2}(8$, $N=299)=6.09, p=.637$, indicating that the families' demographic variables were unable to distinguish between participants who were successful and those who were not. Block 2 was significant, $X^{2}(9, N=$ $299)=60.26, p \leq .001$, and correctly classified $72.6 \%$ of cases. One of the predictor variables, the CBS score (child symptom frequency), made a unique contribution to the model. This predictor recorded an odds ratio of 1.29 , indicating that for every point scored on the CBS, the parent(s) were 1.29 times more likely to demonstrate early success in treatment, controlling for other factors in the model. Block 3 also was significant, $\mathrm{X}^{2}(10, N=299)=86.31, p \leq .001$, and correctly classified $79.6 \%$ of cases. Two of the predictor variables-the ECBS 
and TBS scores-made a unique statistically significant contribution to the model. Again, frequency of child symptoms was the strongest predictor of early treatment success, recording an odds ratio of 1.37 . This indicated that for every additional point scored on the CBS, the parent(s) were 1.37 times more likely to be doing well in early treatment, controlling for other factors in the model. The TBS score was also a predictor of termination appropriateness, with an odds ratio of .876. This indicated that for every additional point scored on the TBS, the parent(s) were .876 times more likely to be successful, controlling for other factors in the model. We collect the CBS at every session so we do not lose data in cases of early termination. 
NOT THE PUBLISHED VERSION; this is the author's final, peer-reviewed manuscript. The published version may be accessed by following the link in the citation at the bottom of the page.

Table 2

Logistic Regression Analysis of Predictors of Treatment Success

\begin{tabular}{|c|c|c|c|c|c|c|c|}
\hline \multirow[b]{2}{*}{ Predictor } & \multirow[b]{2}{*}{$d f$} & \multirow[b]{2}{*}{ Wald } & \multirow[b]{2}{*}{$p$} & \multirow[b]{2}{*}{$\beta$} & \multirow{2}{*}{$\begin{array}{c}\text { Odds } \\
\text { ratio }\end{array}$} & \multicolumn{2}{|c|}{$95 \% \mathrm{CI}$} \\
\hline & & & & & & Lower & Upper \\
\hline \multicolumn{8}{|l|}{ Block 1} \\
\hline Child's age & 1 & .078 & .780 & .032 & 1.03 & .825 & 1.29 \\
\hline \multicolumn{8}{|l|}{ Child's race } \\
\hline African American & 1 & .202 & .653 & .172 & 1.19 & .561 & 2.51 \\
\hline Latino & 1 & .023 & .879 & -.066 & .936 & .399 & 2.20 \\
\hline Multiracial & 1 & .006 & .940 & .034 & 1.03 & .430 & 2.49 \\
\hline Child's gender & 1 & 1.41 & .236 & -.309 & .734 & .440 & 1.22 \\
\hline Developmental delay & 1 & .028 & .867 & .050 & 1.05 & .588 & 1.88 \\
\hline Public assistance & 1 & 3.54 & .060 & .704 & 2.02 & .971 & 4.21 \\
\hline Caregiver age & 1 & .206 & .650 & -.007 & .993 & .965 & 1.02 \\
\hline \multicolumn{8}{|l|}{ Block 2} \\
\hline Child's age & 1 & 2.04 & .153 & .179 & 1.20 & .936 & 1.53 \\
\hline \multicolumn{8}{|l|}{ Child's race } \\
\hline African American & 1 & .881 & .348 & -.406 & .666 & .286 & 1.56 \\
\hline Latino & 1 & .015 & .903 & -.059 & .943 & .366 & 2.43 \\
\hline Multiracial & 1 & .067 & .796 & -.130 & .879 & .329 & 2.35 \\
\hline Child's gender & 1 & .004 & .951 & -.018 & .983 & .559 & 1.73 \\
\hline Developmental delay & 1 & .292 & .589 & .181 & 1.20 & .622 & 2.31 \\
\hline Public assistance & 1 & 1.18 & .278 & .444 & 1.56 & .699 & 3.48 \\
\hline Caregiver age & 1 & .064 & .800 & -.004 & .996 & .964 & 1.03 \\
\hline ECBS CBS & 1 & 43.66 & $.000^{\circ}$ & .253 & 1.29 & 1.20 & 1.39 \\
\hline \multicolumn{8}{|l|}{ Block 3} \\
\hline Child's age & 1 & 2.12 & .145 & .190 & 1.21 & .937 & 1.56 \\
\hline \multicolumn{8}{|l|}{ Child's race } \\
\hline African American & 1 & .026 & .871 & -.073 & .930 & .386 & 2.24 \\
\hline Latino & 1 & .015 & .902 & -.061 & .940 & .352 & 2.51 \\
\hline Multiracial & 1 & .000 & .998 & -.001 & .999 & .360 & 2.77 \\
\hline Child's gender & 1 & .018 & .895 & .040 & 1.04 & .577 & 1.88 \\
\hline Developmental delay & 1 & .000 & .991 & .004 & 1.00 & .498 & 2.02 \\
\hline Public assistance & 1 & 1.99 & .159 & .617 & 1.85 & .786 & 4.37 \\
\hline Caregiver age & 1 & .126 & .722 & -.006 & .994 & .960 & 1.03 \\
\hline ECBS CBS & 1 & 51.40 & $.000^{\circ}$ & .313 & 1.37 & 1.26 & 1.49 \\
\hline TBS score & 1 & 22.61 & $.000^{\circ}$ & -.133 & .876 & .829 & .925 \\
\hline
\end{tabular}

Note. $\quad$ ECBS CBS $=$ Challenging Behavior Scale of the Early Childhood Behavior Screen; TBS $=$ Treatment Barriers Scale.

${ }^{*} p \leq .001$.

We decided to follow the early successful and unsuccessful families until they terminated treatment. Early successful families ( $M=$ $8.81, S D=3.78$ ) participated in significantly more treatments sessions than unsuccessful families $(M=7.41, S D=2.97), t(328)=3.71, p$ $<.001$. An analysis of covariance was used to assess scores on the CBS between early successful and unsuccessful families at the final treatment session with the pretest scores as the covariate. As expected, the results were significant, $F(1,3)=69.35, p<.001$, with

Clinical Practice in Pediatric Psychology, Vol 4, No. 3 (September 2016): pg. 249-262. DOI. This article is (C) American Psychological Association and permission has been granted for this version to appear in e-Publications@Marquette. American Psychological Association does not grant permission for this article to be further copied/distributed or hosted elsewhere without the express permission from American Psychological Association. 
the early successful families having lower adjusted posttreatment scores $(M=16.46)$, meaning less-frequent behavior problems, compared to the early unsuccessful families (adjusted posttreatment $M$ $=21.02)$. We also compared Cohen's treatment effect sizes from their pretreatment CBS scores to treatment termination and found the early successful group had a very large treatment effect size (1.71) compared to a more modest effect size for the early unsuccessful group (0.42). However, these data also suggested that at least for some of the early unsuccessful children, they did improve somewhat from treatment.

\section{Discussion}

It is the goal of every mental health professional who works with young children with significant behavior problems to reduce them and alleviate their caregiver's stress. There are a number of welldeveloped, evidenced-based, parent and child therapy (PCT) programs that have a proven record of accomplishing this goal (e.g., Harris, Fox, \& Love, 2015). A common element of these programs is the importance of making changes in the parenting knowledge and behavior of caregivers, which in turn will result in the children reducing their challenging behaviors. Unfortunately, for a variety of reasons, many caregivers drop out of treatment before they and their children can receive the full benefits of these programs. Directly addressing factors that interfere with a family's treatment completion could add an important dimension to evidence-based PCT programs. Moreover, if young children with behavior problems are not making progress by the third treatment session, clinicians should begin to question the extent to which caregivers are implementing recommended treatment strategies.

This study was the first step in the development of the Treatment Barriers Scale (TBS), a brief clinician-completed screening tool designed to identify barriers early in treatment for low-income, urban, minority families receiving PCT for their young child's challenging behaviors. The initial analyses of the TBS resulted in two empirically derived factors: Treatment Process Barriers and Operational Barriers. The treatment process factor allows practitioners to screen early in treatment for the caregivers' level of commitment to

Clinical Practice in Pediatric Psychology, Vol 4, No. 3 (September 2016): pg. 249-262. DOI. This article is (C) American Psychological Association and permission has been granted for this version to appear in e-Publications@Marquette. American Psychological Association does not grant permission for this article to be further copied/distributed or hosted elsewhere without the express permission from American Psychological Association. 
the process of therapy, including their motivation to engage in treatment, attendance in treatment sessions, participation in treatment, and implementation of treatment techniques. This factor was the stronger of the two factors. Caregivers scoring high on this factor need to be counseled early in treatment about the necessity of their full engagement for optimal success. Clinicians are encouraged to temporarily suspend treatment for these families and have a candid discussion about the importance of the caregivers' participation and use problem solving to determine whether barriers can be reduced or eliminated. For some families, they may not have fully understood their critical role in treatment success and are not ready to fully participate at the present time. In these cases, we have given permission without judgment for these families to put continued treatment on hold until their family situation has improved (e.g., child recovers from an illness, pregnant mother delivers her baby, family finds more suitable housing, pending court proceedings are concluded). It may be necessary to have repeated discussions, along with a clear termination policy (e.g., treatment will be terminated after three missed unexcused sessions and a letter will be sent to document this termination), for families that consistently demonstrate signs of treatment noncompliance (e.g., not engaged during sessions, high noshow or cancellation rates, failure to implement recommended treatment strategies).

The TBS Operational Barriers factor allows practitioners to identify structural barriers that may be influencing the caregiver's ability to learn and/or focus on treatment, including routines in the home, degree to which basic needs are being met, amount of supervision provided in the home, level of caregiver cooperation, and other caregiver characteristics such as physical and mental health, learning ability, and ability to manage stress. This second factor advises clinicians to recognize these barriers early in treatment to be able to advocate for the family by providing appropriate resources to address these obstacles as quickly as possible (e.g., referring the caregiver to an individual counselor, providing education about food pantries or temporary housing options, connecting the family with child care or school programs-these advocacy services and others would benefit from interdisciplinary collaboration with other professionals such as social workers who have expertise in this area).

Clinical Practice in Pediatric Psychology, Vol 4, No. 3 (September 2016): pg. 249-262. DOI. This article is (C) American Psychological Association and permission has been granted for this version to appear in e-Publications@Marquette. American Psychological Association does not grant permission for this article to be further copied/distributed or hosted elsewhere without the express permission from American Psychological Association. 
NOT THE PUBLISHED VERSION; this is the author's final, peer-reviewed manuscript. The published version may be accessed by following the link in the citation at the bottom of the page.

Overall, the combined TBS score was found to be predictive of early treatment success.

The finding suggesting that having more-severe challenging behaviors at intake predicted early success in treatment was unexpected and inconsistent with other research (Ruma, Burke, \& Thompson, 1996). However, there are several reasons this result may have occurred. First, it may be that less-problematic children are treated more quickly, and once their behaviors are "good enough," their caregivers drop out of treatment (Kazdin \& Wassell, 1999). Alternatively, it may be that parents of children with more-problematic behaviors are in greater distress and as a result may be more motivated to participate in treatment to decrease their child's challenging behaviors. Also, it is likely that children with severe problem behaviors at pretest were more likely to experience early treatment success as a result of the definition used in this study. Finally, the Early Pathways Program is unique in that it is delivered in the home of the parent rather than in a clinic or a group setting. Thus, the important therapeutic alliance in treatment participation (Robbins, Turner, Alexander, \& Perez, 2003) may have been easier to develop and maintain in this one-on-one format in a familiar and comfortable setting for families.

\section{Limitations}

There were a number of limitations to this preliminary study on the development of a new scale to measure treatment barriers for a diverse sample of families living in poverty. First, the study sample pool was based on consecutive referrals to a clinic and not obtained through random selection. As a result, a self-selection bias may have impacted the results. Second, although the demographic representation of the sample is consistent with the population served by the clinic in this study (Fung et al., 2014), it is not representative of families from different socioeconomic status (SES) levels, racial groups, child ages, geographic areas, or other potentially contributing factors such as the treatment site (e.g., hospital/clinic vs. home) or treatment program (e.g., Early Pathways Program, Parent-Child Interaction Therapy, Triple P-Positive Parenting Program, Child Parent Psychotherapy). However, given the general nature of the TBS items, 
they should have relevance in other treatment settings with different treatment modalities and client populations. More research will be needed to determine whether the TBS has a broader range of applicability than represented in the present study. In order to accomplish this, a representative sample that is stratified by SES, race, child age and gender, and perhaps other factors such as treatment setting would be helpful to determine the extent to which the TBS can be generalized. Third, the findings regarding child symptom frequency may be limited due to the instrument used to measure challenging behavior. Because the ECBS is a self-report measure, parents may tend to overreport their child's challenging behavior to communicate their high frustration levels and need for support. Adding other measures of the child's behavior problems, including clinician ratings of behavior issues and direct observational tools, would begin to address this limitation. Fourth, this study emphasized early treatment success so that clinicians could identify families early in treatment that were not making expected progress and begin to address how to help these families achieve greater success with their children. We also defined early treatment as attending at least three treatment sessions. Future research should also consider families that drop out even before meeting this minimal criterion. Finally, the TBS needs continued development to determine its interrater reliability across clinicians as well as its discriminant, concurrent, and short- and long-term predictive validity. It also would benefit from a confirmatory factor analysis and perhaps be considered as a moderator or mediator in future treatment studies. Despite these limitations, the TBS does appear to have sufficient preliminary psychometric properties to recommend its use in future research and clinical practice.

\section{References}

Carrasco, J. M., \& Fox, R. A. (2012). Varying treatment intensity in a homebased parent and child therapy program for families living in poverty: A randomized clinic trial. Journal of Community Psychology, 40, 621630. $10.1002 /$ jcop. 21492

Colonna-Pydyn, C., Gjesfjeld, C. D., \& Greeno, C. G. (2007). The factor structure of the Barriers to Treatment Participation Scale (BTPS): Implications for future barriers scale development. Administration and

Clinical Practice in Pediatric Psychology, Vol 4, No. 3 (September 2016): pg. 249-262. DOI. This article is (C) American Psychological Association and permission has been granted for this version to appear in e-Publications@Marquette. American Psychological Association does not grant permission for this article to be further copied/distributed or hosted elsewhere without the express permission from American Psychological Association. 
NOT THE PUBLISHED VERSION; this is the author's final, peer-reviewed manuscript. The published version may be accessed by following the link in the citation at the bottom of the page.

Policy in Mental Health and Mental Health Services Research, 34, 563569. 10.1007/s10488-007-0139-6

Fox, R. A., \& Holtz, C. A. (2009). Treatment outcomes for toddlers with behavior problems from families in poverty. Child and Adolescent Mental Health, 14, 183-189. 10.1111/j.1475-3588.2009.00527.x

Fox, R. A., Keller, K. M., Grede, P. L., \& Bartosz, A. M. (2007). A mental health clinic for toddlers with developmental delays and behavior problems. Research in Developmental Disabilities, 28, 119-129. 10.1016/j.ridd.2006.02.001

Fung, M. P., \& Fox, R. A. (2014). The culturally-adapted early pathways program for young Latino children in poverty: A randomized controlled trial. Journal of Latina/o Psychology, 2, 131-145. 10.1037/lat0000019

Fung, M. P., Fox, R. A., \& Harris, S. E. (2014). Treatment outcomes for at-risk young children with behavior problems: Toward a new definition of success. Journal of Social Service Research, 40, 623-641. $10.1080 / 01488376.2014 .915283$

Glascoe, F. P. (2005). Screening for developmental and behavioral problems. Mental Retardation and Developmental Disabilities Research Reviews, 11, 173-179. 10.1002/mrdd.20068

Gresl, B. L., Fox, R. A., \& Fleischmann, A. (2014). Home-based parent-child therapy in low-income African American, Caucasian, and Latino families: A comparative examination of treatment outcomes. Child \& Family Behavior Therapy, 36, 33-50. 10.1080/07317107.2014.878193

Harris, S. E., Fox, R. A., \& Holtz, C. A. (2015). Screening for significant behavior problems in young children living in poverty. Journal of Child and Family Studies. Advance online publication. 10.1007/s10826-0150300-X

Harris, S. E., Fox, R. A., \& Love, J. R. (2015). Early pathways therapy for young children in poverty: A randomized controlled trial. Counseling Outcome Research and Evaluation, 6, 3-17.

$10.1177 / 2150137815573628$

Harrison, M. E., McKay, M. M., \& Bannon, W. M., Jr. (2004). Inner-city child mental health service use: The real question is why youth and families do not use services. Community Mental Health Journal, 40, 119-131. 10.1023/B:COMH.0000022732.80714.8b

Holtz, C. A., Carrasco, J. M., Mattek, R. J., \& Fox, R. A. (2009). Behavior problems in toddlers with and without developmental delays: Comparison of treatment outcomes. Child \& Family Behavior Therapy, 31, 292-311. 10.1080/07317100903311018

Holtz, C. A., \& Fox, R. A. (2012). Behavior problems in young children from low-income families: The development of a new screening tool. Infant Mental Health Journal, 33, 82-94. 10.1002/imhj.20341

Clinical Practice in Pediatric Psychology, Vol 4, No. 3 (September 2016): pg. 249-262. DOI. This article is (C) American Psychological Association and permission has been granted for this version to appear in e-Publications@Marquette. American Psychological Association does not grant permission for this article to be further copied/distributed or hosted elsewhere without the express permission from American Psychological Association. 
NOT THE PUBLISHED VERSION; this is the author's final, peer-reviewed manuscript. The published version may be

accessed by following the link in the citation at the bottom of the page.

Jacobson, N. S., \& Truax, P. (1991). Clinical significance: A statistical approach to defining meaningful change in psychotherapy research. Journal of Consulting and Clinical Psychology, 59, 12-19. 10.1037/0022-006X.59.1.12

Kazdin, A. E., Holland, L., Crowley, M., \& Breton, S. (1997). Barriers to Treatment Participation Scale: Evaluation and validation in the context of child outpatient treatment. Journal of Child Psychology and Psychiatry, 38, 1051-1062. 10.1111/j.1469-7610.1997.tb01621.x

Kazdin, A. E., \& Wassell, G. (1999). Barriers to treatment participation and therapeutic change among children referred for conduct disorder. Journal of Clinical Child Psychology, 28, 160-172. 10.1207/s15374424jccp2802_4

Lanier, P., Kohl, P. L., Benz, J., Swinger, D., Moussette, P., \& Drake, B. (2011). Parent-child interaction therapy in a community setting: Examining outcomes, attrition, and treatment setting. Research on Social Work Practice, 21, 689-698. 10.1177/1049731511406551

McCabe, K. M. (2002). Factors that predict premature termination among Mexican-American children in outpatient psychotherapy. Journal of Child and Family Studies, 11, 347-359.

Nock, M. K., \& Ferriter, C. (2005). Parent management of attendance and adherence in child and adolescent therapy: A conceptual and empirical review. Clinical Child and Family Psychology Review, 8, 149-166. 10.1007/s10567-005-4753-0

Poulou, M. S. (2015). Emotional and behavioural difficulties in preschool. Journal of Child and Family Studies, 24, 225-236. 10.1007/s10826013-9828-9

Reyno, S. M., \& McGrath, P. J. (2006). Predictors of parent training efficacy for child externalizing behavior problems-A meta-analytic review. Journal of Child Psychology and Psychiatry, 47, 99-111. 10.1111/j.1469-7610.2005.01544.X

Robbins, M. S., Turner, C. W., Alexander, J. F., \& Perez, G. A. (2003). Alliance and dropout in family therapy for adolescents with behavior problems: Individual and systemic effects. Journal of Family Psychology, 17, 534-544. 10.1037/0893-3200.17.4.534

Ruma, P. R., Burke, R. V., \& Thompson, R. W. (1996). Group parent training: Is it effective for children of all ages?Behavior Therapy, 27, 159-169. 10.1016/S0005-7894(96)80012-8

Snell-Johns, J., Mendez, J. L., \& Smith, B. H. (2004). Evidence-based solutions for overcoming access barriers, decreasing attrition, and promoting change with underserved families. Journal of Family Psychology, 18, 19-35. 10.1037/0893-3200.18.1.19

Tabachnick, B. G., \& Fidell, L. S. (2007). Using multivariate statistics (5th ed.). Boston, MA: Allyn \& Bacon.

Clinical Practice in Pediatric Psychology, Vol 4, No. 3 (September 2016): pg. 249-262. DOI. This article is (C) American Psychological Association and permission has been granted for this version to appear in e-Publications@Marquette. American Psychological Association does not grant permission for this article to be further copied/distributed or hosted elsewhere without the express permission from American Psychological Association. 
NOT THE PUBLISHED VERSION; this is the author's final, peer-reviewed manuscript. The published version may be accessed by following the link in the citation at the bottom of the page.

Thomas, R., \& Zimmer-Gembeck, M. J. (2007). Behavioral outcomes of parent-child interaction therapy and Triple $\mathrm{P}$-Positive Parenting Program: A review and meta-analysis. Journal of Abnormal Child Psychology, 35, 475-495. 10.1007/s10802-007-9104-9

Clinical Practice in Pediatric Psychology, Vol 4, No. 3 (September 2016): pg. 249-262. DOI. This article is (C) American Psychological Association and permission has been granted for this version to appear in e-Publications@Marquette. American Psychological Association does not grant permission for this article to be further copied/distributed or hosted elsewhere without the express permission from American Psychological Association. 